\title{
Sedation by Non-Anesthesiologists: Are Opioids and Benzodiazepines Outdated?
}

\author{
M. Dinis-Ribeiro ${ }^{\mathrm{a}} \quad$ J.J. Vargo ${ }^{\mathrm{b}}$ \\ anstituto Portugues de Oncologia do Porto, Faculdade de Medicina da Universidade do Porto, Porto, Portugal; \\ bSection of Therapeutic Endoscopy, Department of Gastroenterology and Hepatology, Cleveland Clinic Foundation, \\ Cleveland, Ohio, USA
}

\section{Key Words}

Propofol $\cdot$ Midazolam $\cdot$ Opioids

\begin{abstract}
At least 3 systematic reviews have assessed the safety of propofol versus traditional agents used for sedation in gastrointestinal endoscopic procedures. These reviews uncovered a marked variability in study design and found the quality of the included randomized controlled trials to be poor. To date there is no demonstrated difference in the endoscopic safety or efficacy of propofol sedation compared to sedation with benzodiazepine with or without an opioid. However, a trend towards reduced complications and higher levels of satisfaction and cost-effectiveness with propofol during colonoscopies, and higher levels of patient satisfaction and improved efficacy may also be expected by using propofol during upper gastrointestinal endoscopies.

Copyright $\odot 2010$ S. Karger AG, Basel
\end{abstract}

\section{Introduction}

Worldwide, both anesthesiologists and non-anesthesiologists, depending on local or national laws, have been increasingly using propofol to replace classical sedation protocols based on opioids and benzodiazepines. We aimed to summarize current evidence on the safety and efficacy of this option (up to September 2009) by updating systematic reviews previously published [1-3] on this subject.

\section{Methods}

MedLine was searched with a query based on previous manuscripts using key words for endoscopy, sedation and pharmacological agents. Manuscripts comparing propofol alone versus benzodiazepines either alone or in association with narcotics were considered. Previous reviews seem to aggregate data from different lists of manuscripts, but a low quality of manuscripts and variability of criteria were noted in all $[1,3]$.

\section{Safety Outcomes}

For upper gastrointestinal endoscopy, 4 manuscripts compared the use of propofol versus midazolam [4-6] and compared propofol versus midazolam plus narcotic $[7,8]$. No significant differences were noticeable in the incidence of hypoxemia [1,3] or hypotension [3]. Moreover, 6 studies [9-14] assessed the use of propofol versus midazolam plus narcotic during colonoscopies, and significant differences were detected in the incidence of bra-

\section{KARGER}

Fax +4161306 1234

E-Mail karger@karger.ch

www.karger.com
(C) 2010 S. Karger AG, Basel

$0012-2823 / 10 / 0822-0100 \$ 26.00 / 0$

Accessible online at:

www.karger.com/dig
John J. Vargo, MD, MPH, AGAF FACG FACP FASGE, Section of Therapeutic and Hepatobiliary Endoscopy, Department of Gastroenterology and Hepatology Digestive Disease Institute, Cleveland Clinic 9500 Euclid Ave., Cleveland, OH 44195 (USA) Tel. +1 216445 5012, Fax +1 2164446284 
dycardia, hypotension or hypoxemia [3, 12]. Qadeer et al. [3] also aggregated data on ERCP/EUS and described the same similarity in safety outcomes.

\section{Efficacy}

Procedure times were similar when comparing those patients with propofol versus midazolam plus narcotic, but recovery times were shorter for propofol $[1,12]$. More recently, a randomized trial of 60 patients described that improved efficacy may be expected by using propofol (vs. midazolam) in upper gastrointestinal endoscopies [15]. Meining et al. [15] randomized 30 patients for midazolam and 30 patients for propofol and assessed with a scale the quality of performed endoscopies (via videotape). Significantly better scores for assessments of the z-line, duodenal bulb and folds were noted in the propofol arm. Four patients $(13 \%)$, however, randomized to midazolam, did not perform the examination.

\section{Patient and Doctor Satisfaction Levels}

Again, no differences were reported as significant for patient satisfaction and willingness to repeat the procedure when considering the four manuscripts in upper gastrointestinal endoscopy [4-8]. However, considering the studies evaluating colonoscopies [9-14], a higher satisfaction and a lower frequency of memory of the procedure was described by those patients given propofol.

\section{Economic Analysis}

When compared to propofol alone, the use of meperidine and midazolam was dominated by a cost-effectiveness standpoint even when accounting for added personnel required for propofol administration [8]. By using economic modeling, propofol-based sedation for colonoscopy was found to be more profitable than other combinations, mostly due to the enhanced recovery time [16].

\section{Conclusion}

Although the reports taken into account were of low quality, there is to date no demonstrated difference in endoscopic safety or efficacy with propofol sedation compared to sedation with a benzodiazepine with or without an opioid. However, a trend towards the reduction of complications, higher levels of satisfaction and cost-effectiveness for the use of propofol during colonoscopies, and higher levels of patient satisfaction and improved efficacy may be expected by using propofol during upper gastrointestinal endoscopies.

\section{References}

1 McQuaid KR, Laine L: A systematic review and meta-analysis of randomized, controlled trials of moderate sedation for routine endoscopic procedures. Gastrointest Endosc 2008;67:910-923.

2 Singh H, Poluha W, Cheung M, et al: Propofol sedation during colonoscopy. Cochrane Database Syst Rev 2008;8:CD 006268.

$\checkmark 3$ Qadeer MA, Vargo JJ, Khandwala F, et al: Propofol versus Traditional Sedative Agents for Gastrointestinal Endoscopy: A MetaAnalysis. Clin Gastroenterol Hepatol 2005;3: 1049-1056.

4 Kotzampassi K, Kapanidis N, Argiriadou E, et al: The sedative features of propofol and midazolam for upper gastrointestinal endoscopy: a comparative study. Hellenic J Gastroenterol 1997; 10:64-67.

$\checkmark 5$ Carlsson U, Grattidge P: Sedation for upper gastrointestinal endoscopy: a comparative study of propofol and midazolam. Endoscopy $1995 ; 27: 240-243$.

6 Chin NM, Tai HY, Chin MK: Intravenous sedation for upper gastrointestinal endoscopy: midazolam versus propofol. Singapor Med J 1992;33:478-480.
7 Patterson KW, Casey PB, Murray JP, et al: Propofol sedation for outpatient upper gastrointestinal endoscopy: comparison with midazolam. Br J Anaesth 1991;67:108-111.

$>8$ Vargo JJ, Zuccaro G Jr, Dumot JÁ, et al: Gastroenterologist-administered propofol versus meperidine and midazolam for advanced upper endoscopy: a prospective, randomized trial. Gastroenterology 2002;123:8-16.

$>9$ Riphaus A, Gstettenbauer T, Frenz MB, et al: Quality of psychomotor recovery after propofol for colonoscopy during monitored anesthesia care? Endoscopy 2006;38:677-683.

10 Ulmer BJ, Hansen JJ, Overley CA, et al: Propofol versus midazolam/fentanyl for outpatient colonoscopy: administration by nurses supervised by endoscopists. Clin Gastroenterol Hepatol 2003;1:425-432.

11 Sipe BW, Rex DK, Latinovich D, et al: Propofol versus midazolam/meperidine for outpatient colonoscopy: administration by nurses supervised by endoscopists. Gastrointest Endosc 2002;55:815-825.
2 Hsieh YH, Chou AL, Lai YY, Chen BS, Sia SL, Chen IC, Chang YL, Lin HJ: Propofol alone versus propofol in combination with meperidine for sedation during colonoscopy. J Clin Gastroenterol 2009;43:753-757.

13 Moerman AT, Foubert LA, Herregods LL, et al: Propofol versus remifentanil for monitored anaesthesia care during colonoscopy. Eur J Anaesthesiol 2003;20:461-466.

14 Gasparovic S, Rustmovic N, Opacic M, et al: Comparison of colonoscopies performed under sedation with propofol or with midazolam or without sedation. Acta Med Austriaca 2003;30:13-16.

15 Meining A, Semmler V, Kassem AM, et al: The effect of sedation on the quality of upper gastrointestinal endoscopy: an investigatorblinded, randomized study comparing propofol with midazolam. Endoscopy 2007;39: 345-349.

16 Vargo JJ, Bramley T, Meyer K, et al: Practice efficiency and economics. The case for rapid recovery sedation agents for colonoscopy in a screening population. J Clin Gastroenterol 2007;41:591-598. 